\title{
Introduction: philosophy of science in practice
}

\author{
Rachel Ankeny • Hasok Chang • Marcel Boumans • \\ Mieke Boon
}

Published online: 28 September 2011

(C) Springer Science+Business Media B.V. 2011

Philosophy of science is booming - at least in sheer quantitative terms, such as the numbers of scholars and professional organizations associated with the field. On the surface, one might attribute these trends to the concurrent growth of science itself, along with the large amounts of funding committed to scientific research and the lasting cultural power of scientific paradigms in the late 20th and early 21st centuries. Yet, much work in the philosophy of science continues in nearly complete isolation from real scientific practice. The Society for Philosophy of Science in Practice (SPSP) grew out of a recognition of the need to promote the philosophical study of "science in practice", by which the organizers of the Society meant both scientific practice and the functioning of science in practical realms of life. Despite occasional exceptions such as some recent literature on models, experimentation, and measurement which have engaged in detailed consideration of scientific practices in pursuit of their philosophical points, concern with practice has tended to fall outside the mainstream of Anglophone analytic philosophy of science. SPSP was founded with the aim of changing this situation, through the promotion of

R. Ankeny $(\bowtie)$

School of History \& Politics, University of Adelaide, Napier Building, The University of Adelaide, Adelaide, SA 5005, Australia

e-mail: rachel.ankeny@adelaide.edu.au

H. Chang

Department of History and Philosophy of Science, University of Cambridge, Free School Lane, Cambridge CB2 3RH, UK

e-mail: hc372@cam.ac.uk

M. Boumans

Faculty of Economics and Business, University of Amsterdam, Valckenierstraat 65-67, 1018 XE

Amsterdam, The Netherlands

e-mail:m.j.boumans@uva.nl

M. Boon

Department of Philosophy, University of Twente, Postbox 217, 7500 AE Enschede, The Netherlands e-mail: m.boon@utwente.nl 
conscious, detailed, and systematic study of scientific practice that nevertheless does not dispense with concerns about truth and rationality.

This special issue of the EJPS brings together a selection of papers presented at the 2nd Biennial Conference of SPSP, which was held in June 2009 at the University of Minnesota in Minneapolis, where Douglas Allchin was the chief local organizer. (For information about other conferences we have held, please see the SPSP website: http://www.utwente.nl/gw/spsp). The eight authors of the papers presented here are based in the US, France, Canada, Finland and the Netherlands, and they are women at various stages of their careers, ranging from a $\mathrm{PhD}$ student to full professors. It is a remarkable coincidence that all of the authors are women, especially as the gender mix at the conference itself was about equal. However, the fact that such a coincidence was possible at all does reflect something about the inclusive and innovative spirit in which SPSP has developed. The purpose of this brief introduction is twofold: firstly to present a concise view of the vision of 'philosophy of science in practice' pursued by SPSP, and secondly to introduce the topics of the individual papers in the issue and indicate how they fit into that vision.

In many of its traditional forms, philosophy of science has focused on the relation between scientific theories and the world, oftentimes to the neglect of scientific practice. In contrast, in social studies of science and technology the dominant trend has been to examine scientific practice as a human creation, sometimes wilfully disregarding the world except as a product of social construction. Both of these approaches have their merits, but they each offer only a limited view neglecting some important perspectives or approaches which are necessary for the development of a fuller picture of science. If we are interested in exploring the assumptions and methods underlying the sciences, it is essential not only to explore the theories and results produced by scientists, but the processes by which they came to these conclusions. And what we learn from history of science is that scientific practices should be evaluated in their historical contexts reaching up to the present moment. Without excavating underneath the tidy surface of published papers or finalized theories, it is extremely difficult to identify these processes. SPSP is dedicated to fostering the pursuit of a philosophy of science that considers theory, practice and the world simultaneously, and never in isolation from each other.

The direction of philosophy of science we advocate is not entirely new and clearly has prestigious forerunners. For example, naturalistic philosophy of science has often emphasized the need to study scientific practices. In integrated approaches to the history, philosophy and sociology of science, much philosophical attention has been paid to actual scientific practices. Outside of the philosophy of science, pragmatists, ordinary-language philosophers and followers of the later Wittgenstein have attempted to ground truth and meaning in practices. And those in the Continental philosophical traditions often have also emphasized the need to consider experience and practice, as well as rejecting the positivist traditions which they view as privileging science unduly and taking scientific progress for granted. Scholars participating in SPSP activities have been making conscious efforts to inject these lines of thought into analytic philosophy of science.

In order to understand the implications of the SPSP approach, it is necessary to consider what is meant by 'practice.' Practice consists of organized or regulated activities aimed at the achievement of certain goals. Therefore, any useful 
investigations of a particular form of practice must elucidate what kinds of activities are associated with and required for the generation of knowledge in that domain. Traditional debates in the philosophy of science concerning epistemological concepts such as truth, fact, belief, certainty, observation, explanation, justification, evidence, and so on may be usefully re-framed in terms of activities. Rather than asking abstract or theoretical questions about the appropriate scientific standards for evidence, recasting the questions of interest in terms of activities allows us to explore various (and often competing) approaches to the generation and weighing of evidence. Examining the goals underlying the activities associated with science also forces us to focus not only on epistemological considerations but also on the values, norms, and ideals inherent in the pursuit of scientific knowledge. Further, it encourages us to question the metaphysical and ontological assumptions underlying these practices rather than taking them as obvious or as unquestionable 'givens.' In short, focusing on practice allows philosophy of science to return to fundamental issues which have increasingly become neglected in favour of a relatively narrow preferred approach to the field which is largely epistemic, highly theoretical, and often overlooks the implications of the sciences as practiced.

In our approach to the philosophy of science, it is crucial to have productive interactions between philosophical analyses and the study of actual scientific practices, past and present. This requirement provides a strong rationale for cultivating the participation of practicing scientists, engineers, policymakers, and others at the 'coal face' of science and practice. We aim not only to learn from the experiences and understandings of these practitioners, but encourage them to become more reflective about their practices, as well as the underlying assumptions and the implications of these practices. We hope that philosophy of science can increasingly be viewed as relevant and useful for scientific practitioners.

Practice, of course, happens in the real world, and SPSP is eager to encourage investigations not only of the acquisition and validation of knowledge, but also of the use of such knowledge in the material and social world. Our concern is not only about how pre-existing knowledge gets applied to practical ends, but also about how knowledge itself is fundamentally shaped by its intended uses. Consequently, it is critical to break down traditional barriers between the 'pure' and 'applied' sciences, between the 'natural' and the 'social' sciences, and between 'science' and 'technology,' in order to allow us to be more reflective about the extent to which and the ways in which all areas of science may be shaped by the uses to which the knowledge generated through scientific research may be put.

We also seek a more inclusive and integrated philosophy of science. At times there has been lopsided attention to certain areas of science, held up as exemplars for all science in general without adequate reflection on their limitations. The traditional focus on fundamental physics, as well as the more recent focus on certain subfields within biology, have distorted our view of science and of scientific practice, and may well have contributed to the canalization of approaches described above as typical of traditional Anglophone philosophy of science. There has been a tendency for some subfields and approaches to be considered by some to be more marginal, such as the philosophy of medicine and the philosophy of technology due to their connections to applications of science, or the philosophy of the social sciences for its subject matter not being really 'scientific', or feminist perspectives as being too relativistic or in 
some sense non-analytic. Hence scholars working in these fields have created their own venues for exchange and publication. In contrast, SPSP advocates re-integration of various subfields and approaches within the philosophy of science. It aims to encourage the examination of a range of scientific fields including economics and other social or human sciences, the engineering sciences, and the medical sciences, as well as relatively neglected areas within biology and physics, using the full range of methods and theories available to us. At a metalevel, we seek to foster reflection on our methodologies for examining science and its practices, including limitations and prospects for learning from other disciplinary traditions devoted to the study of science such as sociology of science, science and technology studies, public understanding of science, and history of science.

The papers included in this special issue represent some of the main themes that have begun to emerge as SPSP has taken shape and grown. For instance, one key theme is the importance of understanding how human artefacts, such as conceptual models, laboratory instruments, linguistic constructs, and scientific standards, mediate between theories and the world, and the role that these artefacts play both in the shaping of scientific practice and of scientific theories. The paper by Tarja Knuuttila and Mieke Boon examines one such artefact that has been revisited numerous times in both the history and the philosophy of science, Sadi Carnot's ideal heat engine. They use this example to focus on explaining how and why models give us useful knowledge through scientific practice, arguing that what they term an 'artefactual' approach to modelling is required since traditional, representational approaches are either misleading or too minimal depending on how representation is defined. Isabelle Peschard's essay focuses on modelling as an activity, going beyond the representational relationship between the model and the target object. She contends that models should be regarded as elements of an 'epistemic space' composed of models of phenomena and activities of modelling, and that the worth of a model depends on the difference it makes in this epistemic space with respect to the investigation of scientifically significant problems. Her examples are drawn from both abstract and experimental models in fluid mechanics, with a particular focus on models which are used in the construction of other models, which she claims is the most common way in which models can 'make a difference.'

As noted above, there are traditions within philosophy which we view as predecessors or inspirations for the current SPSP mandate, including pragmatism. Amy L. McLaughlin's paper supports this vision in its investigation of the pragmatist recommendations in relation to the proper way to conduct scientific inquiry. She examines Charles Sanders Peirce's ideas on the economy in determining which experimental tests to perform, and shows that they reveal traces of his broader epistemological recommendation to pursue nature's resistance to our ideas. Her discussion hence makes a contribution to deepening our understanding of Peirce's philosophy at the same time as providing practical guidance for conducting research under economical or other constraints.

The essays by Monica Aufrecht and Léna Soler both engage with SPSP's metalevel goal of fostering a wider range of methodologies and approaches available to philosophers of science in order to further our understanding of science and its practices. Aufrecht examines a debate related to the legitimacy of feminist approaches to philosophy of science. She revisits the classic 'context of discovery' 
and 'context of justification' distinction as deployed within this debate, and concludes that the use of the context distinction is deeply ambiguous and thus masks underlying debates about naturalism as well as the nature of justification. She makes the further point that the context distinction might serve as an underlying, often unspoken, motivation for many who continue to question the turn to scientific practice (such as that being advocated through SPSP). Soler investigates the tacit dimension of knowledge, which has been highlighted by Michael Polanyi and Harry Collins especially. She argues that the irreducibly tacit presuppositions and corporal skills inevitably involved in experimental practices create what she calls 'opacity' in experimental practices. Examining the consequences of this opacity, she concludes that the stabilization of experimental results is sensitive to the identity of the individuals forming the 'core set' responsible for the stabilization. This opens up the possibility that there may be several different stabilizations, each with sufficient robustness; there are obvious implications for the question of the contingency of scientific results.

Finally, the contributions by Kirstin Borgerson and Miriam Solomon both use medicine and its practice as the window for examining fundamental epistemological issues in the philosophy of science as well as their implications for science policy and practice. Borgerson defends a modified version of Helen Longino's critical contextual empiricism (CCE), using evidence from recent medical research to illustrate lessons particularly regarding epistemic diversity. She shows how a rigorous social epistemology such as CCE is indispensable for understanding and assessing contemporary scientific practice, particularly given the various social pressures which influence contemporary biomedical research as well as the critical role of such research in shaping public policy. Solomon develops a critique of evidence-based medicine (EBM), based on a helpful review of the main tenets of EBM and the extant critical literature. She notes a curious discrepancy between the high degree of reliability that is theoretically expected from the techniques advocated in EBM, and the actual results they deliver in practice. She advocates a more instrumental or even pragmatic approach, in which any ranking of evidence is done by reference to the actual, reliability of results.

We hope you will find this issue thought-provoking and perhaps a bit disruptive compared to more traditional scholarship in the philosophy of science. On the whole, the papers we present here are pioneering forays into new directions, rather than the final word on any given topic. Our wish is that they will stimulate further work by readers of this journal by illustrating the kind of philosophy of science that we are attempting to promote in SPSP. 